\title{
IMPACTO SOCIAL Y ECONÓMICO DE LA INDUSTRIA TABACALERA EN EL DEPARTAMENTO DE ESTELÍ
}

\author{
Aldrin Olivas Benavidez \\ Licenciado en Administración \\ Gerente Scandinavian Tobacco Group Esteli S.A. \\ aldrinatwork@yahoo.com
}

\section{RESUMEN}

La ciudad de Estelí posee las características adecuadas para potenciar el desarrollo del sector tabacalero. Este rubro integra la producción primaria y el proceso de transformación para obtener puros de excelente calidad. Desde esta perspectiva, el papel de la mano de obra es fundamental para garantizar la calidad del producto, las operaciones desde la inspección hasta el empaque final son ejecutadas por el personal. El aumento de fábricas procesadoras de tabaco en la región ha posibilitado que la cifra de empleados haya llegado a 30 mil personas, desde la fase agrícola, preindustrial hasta la industrial. Paralelamente a la producción directa del tabaco, son beneficiadas diferentes empresas que de una forma u otra están vinculadas a todo el proceso productivo como: fábricas de cajas, material de empaque para puros, ventas de fertilizantes y químicos. Según algunos estudios, la economía de Estelí depende en un 80\% de la industria del tabaco.

Palabras claves: Tabacalero, puros, calidad, Estelí

\section{INTRODUCCIÓN}

Al norte de la región central de nuestro país, se encuentra la ciudad de Estelí, cabecera del departamento del mismo nombre, a una distancia aproximada de $145 \mathrm{~km}$ de la capital Managua. El departamento goza de un clima fresco y agradable, ubicado en un valle entre montañas y a una altura de $800 \mathrm{~m}$ sobre el nivel del mar, su población es de aproximadamente 200,000 habitantes, caracterizada por su gran hospitalidad y de ser muy emprendedora.

Estelí fue fundada en el llano del Michigüiste en el año 1823. Su nombre proviene de las toponimias que aún abundan en la región, caracterizadas por su aguda pronunciación, como: Quilalí, Yarculí, Yalí, Estelí, que de acuerdo a investigaciones de origen lingüística corresponden a nuestra región. Estelí tiene varias denominaciones entre ellas "río de sangre" que es la más conocida.

Estelí posee ricos suelos en materia orgánica y micronutrientes, además, el clima, es muy favo- rable, todo eso al combinarse hace posible que la calidad en el cultivo y producción del tabaco sea de una excelencia inigualable lográndose que a nivel mundial se le considere entre los mejores del mundo.

\section{DESARROLLO}

Estelí es el principal centro de comercialización, abastecimientos y suministros de la región, se cuenta con numerosas fábricas procesadoras y exportadoras de tabaco que gozan de gran prestigio a nivel mundial, de ahí que se le conozca como la capital del tabaco.

El aumento de fábricas procesadoras de tabaco en la región ha posibilitado que la cifra de empleados haya llegado a 30 mil personas, desde la fase agrícola, preindustrial hasta la industrial.

Paralelamente a la producción directa del tabaco, son beneficiados diferentes empresas que de una forma u otra están vinculadas en todo el proceso productivo como: fábricas de cajas, elaboración 
de material de empaque para puros, ventas de fertilizantes y químicos. Según algunos estudios, la economía de Estelí depende en un $80 \%$ de la industria del tabaco.

Si bien la producción de tabaco ha beneficiado a innumerables familias, no se está exento de que en un momento dado, la producción sea afectada no solamente por problemas de la naturaleza, sino también por factores económicos, como es el caso de la imposición, por vía legislativa de un impuesto de un 54\% en los Estados Unidos, nuestro principal mercado. Esto evidentemente afectará a la industria mundial y local.

En mis años de experiencia en el sector tabaco y como gerente de la empresa tabacalera "Scandinavian Tobacco Group Esteli S.A.” resalto las siguientes observaciones:

- En la última década, el tabaco de Nicaragua ha mejorado notablemente en calidad, eso se aprecia cada año más en el exterior. Es el país con más rápido crecimiento en el mercado Estadounidense, después de República Dominicana y Honduras. Crecimiento aproximadamente entre 25 a 30\% anualmente, situándose como el cuarto mayor exportador de puros elaborados totalmente a mano.

- El nivel de desempleo en la zona norte, incluyendo Estelí, ha disminuido notablemente debido a la demanda de mano de obra que genera la actividad tabacalera para ambos sexos; se estima en un $60 \%$ la participación de la mujer en toda la industria.

- La calidad de vida de las personas involucradas en todo el proceso productivo ha mejorado notablemente por el aumento de su poder adquisitivo.
- Es política de la empresa capacitar permanentemente a todos los trabajadores en el desempeño de sus funciones, lo que contribuye a realizar el trabajo en forma más eficiente y con mejores condiciones.

- Los trabajadores, por derecho en nuestras fábricas gozan de servicios gratuitos de salud, trasporte y los establecidos por la ley.

- Se pretende en la medida de lo posible, en el futuro cercano, ampliar el número de puestos de trabajo con la construcción de nuevas infraestructuras, lo que garantizará nuevas fuentes de empleo y mayores beneficios a la población.

- Además, como empresa, participamos activamente en nuestra comunidad apoyando diversas actividades sociales y ambientales.

\section{CONCLUSIONES}

La zona norte de Nicaragua cuenta con tierras fértiles y condiciones climáticas apropiadas para el cultivo del tabaco. Sumado a la disposición de abundante mano de obra se crea el ambiente propicio para el desarrollo agroindustrial de este rubro.

El sector tabacalero es de suma importancia en el desarrollo de la ciudad de Estelí y ejerce un impacto directo en la economía de la nación, dado que provee de empleos directos e indirectos.

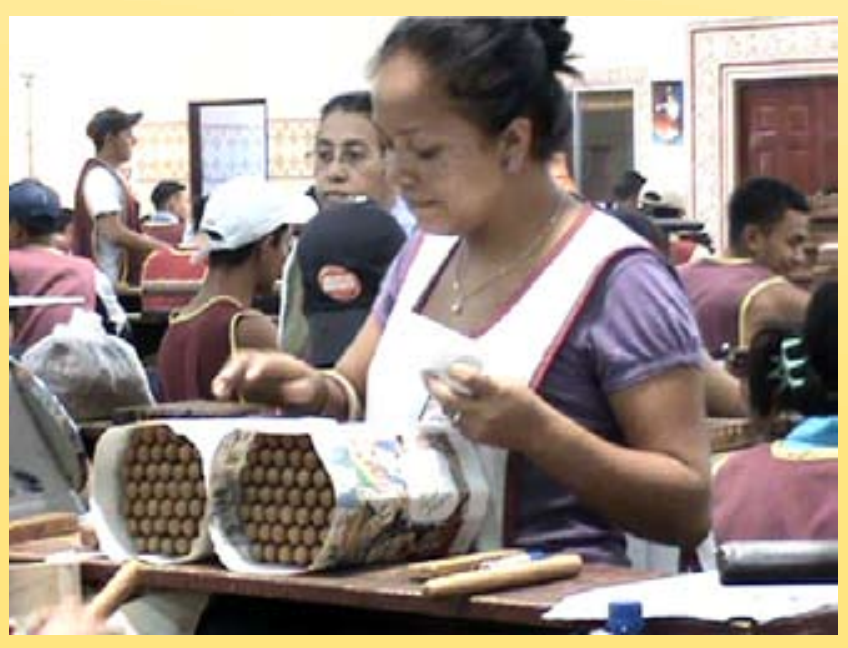

